\title{
Ladin Odununda Çeşitli Ağartıcıların Yüzey Pürüzlülüğü Ve Renk Değişimleri Üzerine Etkisi
}

\author{
Özlem BOZDOĞAN BALÇIK ${ }^{1 *}$ Turgay ÖZDEMİR ${ }^{1}$ \\ ${ }^{1}$ Karadeniz Technical University, Faculty of Forestry, Department of Forest Industry Engineering, Trabzon, Turkey, Türkiye. \\ *D: : https://orcid.org/0000-0002-9898-8154, (D: https://orcid.org/0000-0002-2484-828X
}

Öz: Bu çalışmada, ağartma işlem uygulamasının ülkemizde ticari öneme sahip ağaç türleri odunlarında yüzey pürüzlülüğü ve renk değişimi üzerine etkileri araştırılmıştır. Bu amaçla iğne yapraklı ağaç türlerinden Ladin ve ağartma maddesi olarak, oksalik asit ve perasetik asit kullanılmıştır. Standartla belirtilen boyutlarda deneme örnekleri hazırlanmış ve örnekler üzerinde yüzey pürüzlülüğü ve renk değişimi ölçümleri yapılmıştır. Sonuç olarak Ladin odununda yüzey pürüzlülüğünde oksalik asit ile ağartma iyi sonuç alınırken, renk değişiminde ise perasetik asit ile ağartma iyi sonuç vermiştir.

\section{Anahtar sözcükler: Ladin, oksalik asit, ağartma, perasetik asit.}

\section{The Effect of Various Bleaches on Surface Roughness and Color Changes in Spruce Wood}

Abstract: The aim of this study was to investigate the effects of bleaching treatment on surface roughness and color change of commercially important wood species in Turkey. For this purpose, spruce in which coniferous species and oxalic acid and peracetic acid were used as bleaching agents. Test samples were prepared in the dimensions specified by the standard and surface roughness and color change measurements were made on the samples. As a result, bleaching with oxalic acid in surface roughness of spruce wood was good and peracetic acid bleaching was good in color change. 


\section{GİRIŞ}

Günümüzde üst yüzey işlemleri için, çok sayıda yüzey işlem malzemesi kullanılması yanında, uygulamada da oldukça fazla yöntem geliştirilmiştir. Mobilya endüstrisinde kullanılan çeşitli ağaç türleri de göz önüne alınırsa, üst yüzey işlemlerinin ne kadar karmaşık ve güç olduğu kolayca anlaşılabilir.

Yüzey işlemlerinde malzemelerin (ağaç malzemeler, boya-vernik v.b.) hangi amaç için kullanılacağı bilinmelidir. Aksi durumda bunların seçimi olanaksız veya çok güç olacaktır. Tam açıklık kazanılmamış durumlarda, bu malzemelerin yanında vernik veya boyanın sağlandığı kaynaklardan bilgi alınması uygun olacaktır.

Odunun önemli karakteristiklerinden biri boyanabilme veya verniklenebilme özelliğidir. Bununla birlikte, ağaç türleri çeşitli alet veya makinelerle işlemlerde oldukça farklı davranışlar gösterirler. $\mathrm{Bu}$ nedenle çeşitli kullanım yerleri için birinci derecede önemli bir gösterge olan ağaç malzemenin yüzey karakteristiğinin uygunluğunu belirlemek gerekir. Belirlenen ağaç türlerine ait uygun yüzey işlem özelliklerinin yaygın kullanımları; kaliteli bir ürün için temel olan ve bunların gerektiği mobilya, marangozluk, doğrama veya diğer orman ürünleri gibi üretim alanlarını içerir.

Ağartma işlemleri de çevreyi korumak adına önemli bir işlemdir. odunu istediğimiz renge kolayca elde etmemizi sağlar, eğer ağartma yapmadan odunu tercih ettiğimiz renge ulaştırabilmek için birçok boya ve vernik kullanmamız gerekir. buda ister istemez çevreye zarar verir. bu yüzden ağartıcılar iş yükünü ve kullanılan malzeme miktarını azaltarak istenilen sonuca kolayca ulaşmamıza yardımcı olur.

Suleman ve Rashid (1999), karakavak odununda yüzey işlemlerinin performansını iyileştirmek için çeşitli kimyasallar kullanmışlardır. Bu amaçla örnekler sodyum hidroksit, amonyum klorid ve alüminyum klorid ile işleme tabi tutulmuş daha sonra üzerlerine geleneksel yüzey işlem maddeleri uygulanmıştır. $45^{\circ} \mathrm{C}$ ve $70{ }^{\circ} \mathrm{C}$ de nüfuz etkinliği ve renk değişimleri belirlemiştir. Sonuç olarak, sodyum hidroksit kullanımının iyi sonuç verdiği belirtilmiştir.

Richter, Feist ve Knaebe (1995) yüzey işlemlerinin performans1 üzerine yüzey pürüzlülüğünün etkisini incelemişlerdir. Çalışmada 3 farklı ağaç türünden radyal ve teğet kesitli örnekler elde edilmiş ve 5 farklı yüzey pürüzlülük kategorisinde değerlendirmiş̧lerdir. Örnekleri yağlar ve yarı saydam yüzey işlem maddeleri ile verniklenmişlerdir. Sonuç olarak, yüzey pürüzlülük değeri düşük olan örneklerin daha az yüzey işlem maddesi gerektirdiğini, en iyi boya performansının düşük odun kalitesinde bile zımparalanarak yüzey pürüzlülüğü azaltılmış olan örneklerde sağlandığını belirtmişlerdir.

Pearce (1987), kerestelerin biyolojik, yağmur suyu ve güneş ışı̆̆ı yıkımlamaları veya bozulmalara karşı hazırladığ1 bir yüzey işlemi sisteminin performansını arttırmak amacıyla araştırmalar yapmıştır. Bu amaçla demir esaslı pigment ve alkid reçine karışımını organik çözücülü emprenye maddelerinin içine ilave ederek çift vakum yöntemiyle sarıçam odunu emprenyelenmiş ve dekoratif renklendiriciler ile yağ esaslı verniklerle uygulamaya tabi tutulmuştur. Sonuç olarak; bu yüzey işlem sisteminin güneş ışığı, yağmur bozunumu ve biyolojik degradasyona karşı etkili olacak şekilde dayanıklı, yüzey işlemi görmeyen örneklerin ise yetersiz olduğunu açıklamıştır.

Odun mobilya ve doğrama endüstrilerinde yaygın olarak kullanılan ve temelini teşkil eden ana hammaddedir. Odun kompozit malzemeler mobilya ve kabin tipi mobilya üretiminde yaygın olarak kullanılmasına rağmen, masif odun konstrüksiyon ve doğrama endüstrilerinde hala ana hammadde olma özelliğini sürdürmektedir. Masif odun metal ve plastik malzemelerle karşılaştırıldığında en önemli özelliği işlenebilmesi ve vernik veya boyanabilmesidir. Bunun yanında heterojen yapıya sahip olması işlenme ve boyama işlemlerinde karşılaşılan en önemli sorundur. Tüm üretimlerde odun kullanılmadan önce vernikleme veya boyanma aşamaları öncesi tüm kusurlarından arındırılmalıdır. Bunun için odunda boyanabilme veya verniklenebilme parametrelerinin bilinmesi kullanım açısından önemli olmaktadır (Anonim, 1987; Davis, 1962).

Yüzey işlemi uygulamasının temelde üç amacı vardır; koruma, estetiklik ve hijyeniklik. Bu nedenle odunun yüzeylerin verniklenmesi son ürün eldesinde odunun kullanıldığ 1 tüm endüstrilerde önemli bir parametredir.

Yüzey işlemi yapılmış odunun kalitesi üzerine çeşitli etmenlerin etkileri olmaktadır. Bunlar kullanılan ahşap materyalin özellikleri, uygulanan vernik veya boyanın özellikleri ve ahşap malzeme ile vernik arasındaki etkileşim özellikleridir (Kollmann \& Cote, 1964).

Odunun yüzey işlemleri olarak birçok vernik çeşitleri kullanılmaktadır. Bunlar genelde fiziksel kuruyan, kimyasal sertleşen ve hem kimyasal hem de fiziksel sertleşen tipler olabilmektedir. Ayrıca bunlar tek veya çift karışımlı da olabilmektedir. Sonuçta her vernik tipinin uygulanması sonrası verniğin özelliklerindeki farklılık, odunla etkileşimindeki farklılık nedeniyle sahip olduğu son özellikler farklı olabilmektedir (Jaic vd., 1996).

Bazı araştırmacılar vernik ile ağaç malzeme arasındaki uyum ile ilgili birçok araştırmalar yapmışlardır. Aynı zamanda odunun yapışma direnci ve odun özellikleri arasındaki etkileşim bu konuda yapılan çalışma konularındandır (Meijer \& Militz, 2000). Ayrıca aşınma direnci ve aşınmada meydana gelen ağılık kayıplarının yüzey işlemleri seçiminde önemli bir rol oynadığ belirtilmektedir (Seman, 1996). Yüzey işlem tipi, reçine özellikleri, viskozitenin de yüzey işlem performansını etkileyen özellikler olduğu belirtilmektedir (Allen, 1978; Özdemir \& Mengeloğlu, 2008). 


\section{MATERYAL ve METOT}

Deney Materyali: Çalışmada deney materyali olarak 1 ağaç türü, 1 vernik çeşidi ve 2 farklı ağartma maddesi kullanılmıştır.

Ă̆aç Malzeme: $\mathrm{Bu}$ çalışmada ülkemizde ticari önemi olan, iğne yapraklı ağaç türlerinden Doğu Ladini (Picea oriantalis L.(Link.)) odunu kullanılmıștır.

$\mathrm{Bu}$ amaçla deneylere tabi tutulacak ağaç türlerinin doğal yayılıș gösterdiği Doğu Karadeniz Bölgesi seçilmiştir. $\mathrm{Bu}$ bölgede türlere ait optimal büyümenin olduğu Trabzon, Gümüşhane ve Artvin yöreleri örnek alanlar olarak belirlenmiştir. Örnek alanlarda ağaç türlerinin homojen meşcerelerden olmasına özen gösterilmiş ve basit rastlantı örnekleme yöntemine göre örnek ağaçlar seçilmiştir. Ağaçların seçilmesinde; yaş, bakı, çap ve yükselti vb. yetişme ortamı özellikleri göz önünde tutulmuştur. Yararlanılan ağaçların yetiştiği ortamı en iyi temsil edebilecek, kusursuz gövde yapısına sahip, düzgün ve sağlam ağaçlardan olmasına özen gösterilmiştir. Bunun için ağaç türlerine ait yetişme yerlerinden alınan adet, kesit şeklinin, öz- diri odun durumu ve zımpara etkisini incelemek amacıyla ise, Doğu Ladini, odunundan toplam 60 adet örnek ağaçtan yararlanılmıştır.

Çalışmada yararlanılan örnek ağaçların alındığı yerler ve ağaç türlerine ait genel özellikler TS 4176 esaslarına göre belirlenmiştir.

Vernik Türü: Araştırmada; mobilya ve doğrama endüstrilerinde yaygın olarak kullanılan selülozik esaslı olmak üzere tek vernik çeşidi seçilmiştir. Üretici firmadan takım halinde alınan bu verniğe ait önemli bazı ambalaj özellikleri Tablo 1 'de verilmiştir.

Tablo 1. Selülozik vernik ve bazı ambalaj özellikleri.

\begin{tabular}{lcc}
\hline Vernik Çeşitleri & Selülozik Dolgu Vernik & Selülozik Son Kat Mat Vernik \\
\hline Yoğunluk (gr/cm $\left.{ }^{3}\right)$ & 0,95 & 0,95 \\
Viskosite DIN/CUP4 (sn) & 300 & 301 \\
Toz Kuruması (dk) & $3-5$ & $3-5$ \\
Dokunma Kuruması (dk) & 10 & 10 \\
Zımpara Kuruması (dk) & $2-4$ & $2-4$ \\
Katı Madde Miktarı \% & 30 & 33 \\
\hline
\end{tabular}

A ğartma maddeleri: Bu çalışmada 2 farklı ağartma maddesi kullanılmıştır. Bunlar oksalik asit ve perasetik asittir.

Deney Örneklerinin hazırlanması, Ă̆artma Isslemlerinin Uygulanmast ve Verniklerin Uygulanması: Deney örneklerinin hazırlanacağı ağaçların yaklaşık olarak 2,5-5,5 m. yükseklikleri arasından 1,20-1.50 m boylarında tomruklar alınarak K.T.Ü. Orman fakültesi, Orman Endüstri Mühendisliği laboratuvarına getirilmiş ve bunlardan öz-diri odun ile teğet-radyal kesitlerde olmak üzere şerit testere makinesinde biçilerek, $3 \mathrm{~cm}$ kalınlığında $11 \mathrm{~cm}$ genişliğinde toleranslı boyutta parçalar elde edilmiştir. Daha sonra bu parçalar iyi havalandırılan bir yerde uygun şekilde istif edilerek doğal kurumaya bırakılmıştır.
Doğal kuruması gerçekleşen parçalar $20 \pm 2 \quad \mathrm{C}$ sıcaklık ve $\% 65 \pm 5$ bağıl nem koşullarındaki iklimlendirme odasında değişmez ağırlığa gelinceye kadar bekletilmiş ve rutubetlerinin yaklaşı $\% 12$ olması sağlanmıştır. İklimlendirme işlemleri tamamlanan parçalar planya, kalınlık ve daire testere makinalarında işlenerek 1300x100x20 mm ölçülerine getirilmiştir. Parçalar daire testere makinasında işleme tabi tutularak enine yönde 3 eşit parça olacak şekilde kesilmiş ve her bir parçadan 6 adet olmak üzere 400x100x20 $\mathrm{mm}$ boyutlarında deney parçaları elde edilmiștir. Her bir örnek grubu ağartma maddesinin etkisini araştırmak amacıyla 6 gruba ayrılmış ve bu gruplardan biri kontrol olarak bırakılmış, diğerlerine ise yukarıdan belirtilen ağartma maddeleri sürme yöntemi ile $\mathrm{m}^{2}$ ye $120-150$ gr gelecek şekilde firça ile uygulanmıştır. Uygulama sonrası 1 gün bekletilip daha sonra örnek yüzeyleri 1lık bezle saf su ile silinerek ağartma maddesi kalıntılarından temizlenmişlerdir. Daha sonra vernik uygulamasına geçilmiştir.

Deneylerde kullanılacak verniğin uygulama koşulları ve karışım miktarı üretici firma önerilerine göre yapılmıştır. $\mathrm{Bu}$ amaçla; vernik türünün viskozitesi (DIN Cup $/ 4 \mathrm{~mm} / 20^{\circ} \mathrm{C}^{\prime}$ ye göre) $2 \mathrm{sn}$. ve karışım miktarı ise şekil 2 deki gibi seçilmiştir.

\begin{tabular}{llll}
\hline Vernik Çeșitleri & Vernik (Kısım) & Sertleștirici (Kısım) & İnceltici (Kısım) \\
\hline Selülozik Dolgu Vernik & 100 & 0 & 80 \\
Selülozik Son Kat Mat Vernik & 100 & 0 & 80 \\
\hline
\end{tabular}

Parçalara verniğin uygulanmasında iğne uç çapı 1,8 mm olan alttan depolu püskürtme tabancası kullanılmış ve uygulamadaki hava basıncı 3 atm. olarak seçilmiştir. Uygulamada; püskürtme tabancası parça yüzeylerine dik ve uzaklığı 25-30 cm olacak şekilde paralel hareket ettirilerek vernik kalınlıklarının eşit olmasına özen gösterilmiştir.

Örnek parçaların verniklenmesi endüstriyel uygulamalara göre birim alana $120 \pm 5 \mathrm{~g} / \mathrm{m}^{2}$ olacak şekilde 2 kat dolgu vernikleme ve 1 kat son vernikleme olarak gerçekleştirilmiştir. Her iki dolgu vernikleme uygulaması sonrası örnek parçalar kurutulmuş ve zımparalama işlemlerinde titreşimli el zımpara makinesinden yararlanılmıştır. $\mathrm{Bu}$ amaçla 1. Kat dolgu vernik uygulaması sonrası 220 no'lu, 2. Kat dolgu vernik uygulaması sonrası ise 400 no'lu alüminyum oksitli kâğıt zımpara bantları kullanılmıştır.

Vernik uygulamaları sonrası; selülozik vernikli parçalar 12 saat süre ile $20 \pm 2{ }^{\circ} \mathrm{C}$ derece sicaklık ve \%65+-5 bağıl nem koşullarında kurumaya bırakılmıştır. Uygulamalar atölye ortamında gerçekleştirilmiştir. $\mathrm{Bu}$ amaçla ortamın tozsuz olmasına özen gösterilmiş, aşırı hava akımı, sıcaklık ve bağıl nemden kaçınılmıştır.

Böylece tüm işlemeleri tamamlanan 430x100x20 mm ölçüsündeki bu parçalardan standart boyutlarda deney örnekleri elde edilmiştir. 


\section{Deney Yöntemleri}

Yüzey Pürüzlü̆ğ̈: Bu amaçla her bir ağaç türüne ait 400x100x20 mm boyutundaki toplam 240 adet parçadan yararlanılmıştır. Ölçümler DIN 4768 esaslarına uygun olarak iğne taramalı pürüzlülük aleti (Mitutuyo SJ 301) ile ve örneklerin enine yönde yapılmıștır. (Şekil 2). Pürüzlülük aletinin iğne uç yarıçapı $0,5 \mathrm{~m} * \mathrm{~m}$, iğne uç açısı 90derece Dalga boyu ( $\chi$ ) $2,5 \mathrm{~mm}$ ve ölçme hızı $0,5 \mathrm{~mm} / \mathrm{sn}$ olarak seçilmiştir. Pürüzlülük değerleri Ra, Ry ve $\mathrm{Rz}$ olarak belirlenmiş, istatistik değerlendirmelerde $\mathrm{Rz}$ değerlerinden yararlanılmıştır.

Optik Özelliklerin Belirlenmesi: Renk ölçümleri ISO/CD 5631 standardına uygun olarak yapılmıştır. Renk değerlendirmeleri CIE (Commission Internatıonal de 1'Eclairage) tarafindan 1971 yılında kağıt endüstri için önerilen sistemle $L^{*}$, $a^{*}$ ve $b^{*}$ CIELAB koordinatlarının hesaplanmasıyla gerçekleşmiştir.

$L^{*}, a^{*}$ ve $b^{*}$ renk modeli dikey sarı-mavi ve yeşilkırmızı eksenlerine dayanan dörtgensel koordinatlar kullanılır. L*, a* ve b* renk uzayının iyi dengelenmiş yapısı ,bir rengin aynı zamanda hem yeşil hem kırmızı veya hem mavi hem de sarı olamayacağı teorisi üzerine kurulmuştur. Bunun sonuncunda kırmızı/yeşil veya sarı/mavi sıfatlarını tarif etmek için basit değerler kullanılabilir. CIE L*, $a^{*}$ ve $b^{*}$ da bir rengi gösterirken, $L^{*}$ beyazlık, $a^{*}$ kırmızı/yeşil değerini ve $b^{*}$ sarı/mavi değerlerini gösterir (Şekil 1).

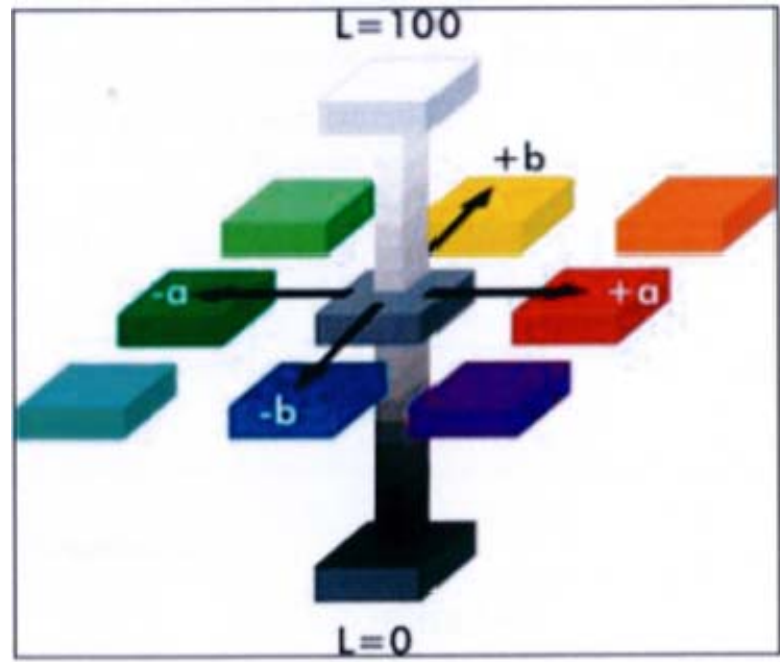

Şekil 1. CIE L*a*b* renk düzlemi (Özcan, 2008).

$\mathrm{L}^{*} \mathrm{a}^{*} \mathrm{~b}^{*}$ sistemine göre,iki renk arasındaki renk farkı veya uzaklık; hesaplanır.

$$
\Delta \mathrm{E}=\left[(\Delta \mathrm{L}) 2+\left(\Delta \mathrm{a}^{*}\right)+\left(\Delta \mathrm{b}^{*}\right)\right] 1 / 2 \text { formüllerine göre }
$$

\section{BULGULAR ve TARTIŞMA}

Ă̆artma işlemleri sonucu örneklerin renk değişimleri: Ladin odununda ağartma işlemleri sonucunda deney örneklerinde elde edilen renk değişimleri Tablo 3 'de verilmiştir.

Tablo 3. Ladin odununda ağartma işlemleri sonucu renk değişimleri.

\begin{tabular}{|c|c|c|c|c|c|c|c|c|c|}
\hline & & \multicolumn{4}{|c|}{ Diri Odun } & \multicolumn{4}{|c|}{ Öz Odun } \\
\hline & & Radyal Kesit & Radyal kesit* & Teğet Kesit & Teğet kesit** & Radyal Kesit & Radyal kesit* & Teğet Kesit & Teğet kesit* \\
\hline & $L$ & 78.73 & 78.50 & 80.76 & 79.51 & 83.74 & 81.35 & 81.36 & 78.98 \\
\hline \multirow[t]{4}{*}{1.00} & $a$ & 6.50 & 7.42 & 4.95 & 6.65 & 4.06 & 6.31 & 5.07 & 6.89 \\
\hline & $b$ & 19.97 & 20.60 & 17.92 & 19.79 & 20.92 & 21.86 & 19.75 & 20.23 \\
\hline & $\Delta E$ & & 1.14 & & 2.82 & & 3.41 & & 3.03 \\
\hline & $L$ & 76.68 & 80.28 & 75.29 & 80.31 & 77.86 & 80.65 & 70.56 & 78.57 \\
\hline \multirow[t]{3}{*}{2.00} & $a$ & 6.93 & 5.20 & 7.14 & 4.93 & 6.21 & 4.67 & 6.18 & 5.11 \\
\hline & $b$ & 19.48 & 22.21 & 19.00 & 21.06 & 20.26 & 21.59 & 19.66 & 21.35 \\
\hline & $\Delta E$ & & 4.84 & & 5.86 & & 3.45 & & 8.26 \\
\hline
\end{tabular}

Renk değişim değerleri ise şekil 4'de verilmiştir.

Yüzey pürüzlïllüğ̈̈: Ladin odununda ağartma işlemleri sonucunda oluşan \% pürüzlülük değerleri Tablo 4'de verilmiştir.

Ladin odununda ağartma işlemlerinin pürüzlülük oranı üzerine, öz ve diri odun, radyal ve teğet kesitte etkilerini incelemek için yapılan varyans analizi sonuçları Tablo 5'de verilmiştir.
Tablo 4. Ladin odununda ağartma işlemleri sonucu pürüzlülük oranlar1.

\begin{tabular}{lccc}
\hline Diri-Öz & Radyal Teğet & 1 & 2 \\
\hline \multirow{3}{*}{ Diri Odun } & \multirow{2}{*}{ Radyal } & 54.674 & 31.136 \\
& & $(9.681)$ & $(3.213)$ \\
\cline { 2 - 4 } & \multirow{2}{*}{ Teğet } & 69.954 & 60.834 \\
& & $(14.613)$ & $(7.207)$ \\
\hline \multirow{2}{*}{ Öz Odun } & \multirow{2}{*}{ Radyal } & 78.502 & 108.620 \\
& \multirow{2}{*}{ Teğet } & $(15.780)$ & $(26.786)$ \\
\cline { 2 - 4 } & & 70.825 & 44.473 \\
& & $(11.747)$ & $(9.050)$ \\
\hline
\end{tabular}


Tablo 5. Ladin odununda ağartma işlemlerinin etkilerini araştırmak için yapılan Varyans analizi sonuçları.

\begin{tabular}{lccccc}
\hline \multicolumn{1}{c}{ Kaynak } & $\begin{array}{c}\text { Kareler } \\
\text { toplamı }\end{array}$ & $\begin{array}{c}\text { Serbestlik } \\
\text { derecesi }\end{array}$ & $\begin{array}{c}\text { Kareler } \\
\text { ortalaması }\end{array}$ & F & Önem düzeyi \\
\hline Öz-diri odun etkisi (A) & 34406,601 & 1 & 34406,601 & 106,938 & $* * *$ \\
Radyal-teğet kesit etkisi (B) & 712,556 & 1 & 712,556 & 2,215 & B.D \\
Ağartma maddesi etkisi (C) & 4925,570 & 4 & 1231,393 & 3,827 & $* *$ \\
AXB & 9687,415 & 1 & 9687,415 & 30,109 & $* * *$ \\
BXC & 20967,353 & 4 & 5241,838 & 16,292 & $* * *$ \\
AxC & 7888,633 & 4 & 1972,158 & 6,130 & $* * *$ \\
AXBXC & 12556,345 & 4 & 3139,086 & 9,756 & $* * *$ \\
Hata & 32174,466 & 100 & 321,745 & & \\
\hline Toplam & $\mathbf{6 5 4 9 8 2 , 4 8 6}$ & $\mathbf{1 2 0}$ & & & \\
\hline
\end{tabular}

$\mathrm{Bu}$ sonuçlara göre, ladin odununda ağartma işlemleri sonucunda \% pürüzlülük değerlerinde, öz ve diri odunun etkisinin \% 0.1 önem düzeyinde etkili olduğu, kesit türünde ise \% 5 yanılma olasılığı ile önemsiz olduğu, ağartma maddelerinin etkisi ise \% 0.1 yanılma olasılığı ile etkili bulunmuştur. Etkiler araştırılan grupların karşılıklı etkileri ise anlamlı bulunmuştur. Etkileri araştırılan grupların Duncan testi sonuçları Tablo 6'da verilmiştir.

Tablo 6. Ladin odununda \% pürüzlülük üzerine ağartma işlemleri sonucu etkili grupların Duncan testi sonuçları.

\begin{tabular}{llcc}
\hline Varyans Kaynakları & & Pürüzlülük oranı & Homojenlik grupları \\
\hline \multirow{2}{*}{ Öz-diri odun } & Öz odun & 83.495 & $\mathrm{~A}$ \\
\cline { 2 - 4 } & Diri odun & 49.629 & $\mathrm{~B}$ \\
\hline \multirow{2}{*}{ Radyal-teğet kesit } & Radyal kesit & 68.999 & $\mathrm{~A}$ \\
\cline { 2 - 4 } & Teğet kesit & 64.125 & $\mathrm{~A}$ \\
\hline \multirow{2}{*}{ Ağartma maddesinin etkisi } & 1 & 68.488 & $\mathrm{~A}$ \\
\cline { 2 - 4 } & 2 & 61.265 & $\mathrm{~B}$ \\
\hline
\end{tabular}

Ducan testi sonuçlarına göre, öz odunda ağartma işlemleri sonucunda daha fazla bir pürüzlülük değişimi meydana gelmiştir. Ağartma maddelerinde oksalik asit ağartma maddesi daha fazla bir pürüzlülük değişimi meydana getirmiştir.

\section{SONUÇ ve TARTIŞMA}

Renk Değişimi: Ağartma işlemleri sonucu elde edilen renk değişimi değerleri Şekil 2'de verilmiştir.

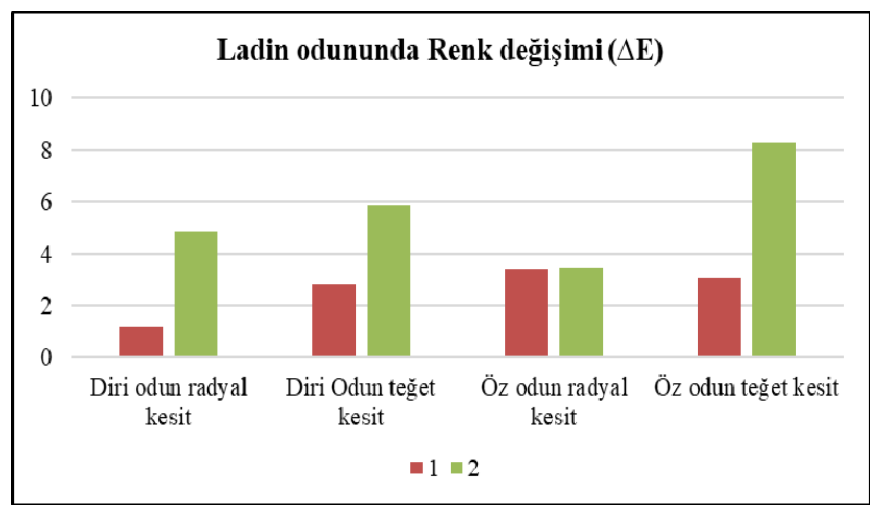

Şekil 2. Ladin odununda renk değişimi $(\Delta \mathrm{E})$ (1 nolu ağartma maddesi: oksalik asit,2 nolu ağartma maddesi: perasetik asit).
Buna göre diri odun radyal kesitte en yüksek renk değişimi perasetik asit ile ağartma $(4,84)$ ağartma işlemi sonucu elde edilirken en düşük ise oksalik asit ile ağartma $(1,14)$ ağartma işlemi sonucu elde edilmiştir.

Diri odun teğet kesitte en yüksek renk değişimi perasetik asit ile ağartma $(5,86)$ ağartma işlemi sonucu elde edilirken, bunu sırasıyla en düşük ise oksalik asit ile ağartma $(2,82)$ ağartma işlemi sonucu elde edilmiştir.

Öz odun radyal kesitte hemen hemen her iki ağartma maddesi de aynı sonucu vermiştir, fakat yine küçük bir farkla yine perasetik asit ile ağartma $(3,45)$ ağartma maddesi en iyi, sonucu vermiştir.

Öz odun teğet kesitte en yüksek renk değişimi perasetik asit ile ağartma $(8,26)$ ağartma işlemi sonucu elde edilirken, en düşük ise oksalik asit ile ağartma $(3,03)$ ağartma işlemi sonucu elde edilmiştir.

Renk değişiminde perasetik asetin daha yüksek performans göstermesinin sebebi okasalik asite göre daha çok aşındırıcı bir ağartma maddesidir.

Yüzey Pürüzlülü̈̆̈̈̈: Ağartma işlemleri sonucu elde edilen yüzey pürüzlülük değerleri Şekil 3'de verilmiştir.

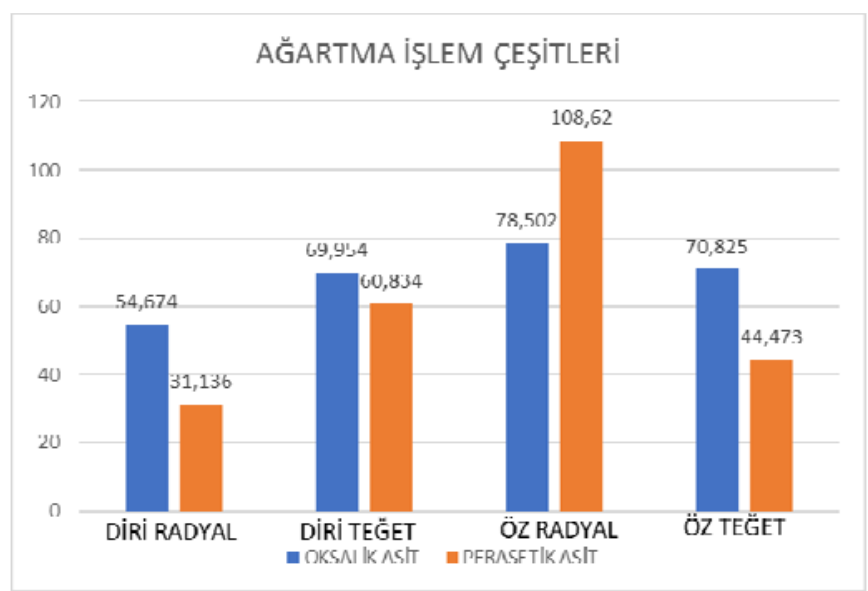

Şekil 3. Ladin odununda \% pürüzlülük değerleri (ağartma sonrası).

Ladin odununda ağartma işlemlerinin \% pürüzlülük üzerine, öz ve diri odun, radyal ve teğet kesitte etkilerini incelemek için yapılan analizlerin sonucuna göre, ladin odununda öz ve diri odun kıyaslandığında en yüksek yüzey pürüzlülüğü öz odunda radyal kesitte perasetik asit ile ağartma $(108,620)$ ağartma işlemi sonucu elde edilmiştir. En düşük yüzey pürüzlülüğü diri odun radyal kesit perasetik asit ile ağartma $(31,136)$ ağartma maddesinde işlemi sonucu elde edilmiştir. Renk değişiminde oksalik asit ile ağartma daha iyi performans göstermiştir, çünkü perasetik asit gibi aşındırma özelliği azdır.

Ladin odununda ağartma işlemlerinin \% pürüzlülük üzerine radyal ve teğet kesitte etkilerini incelemek için yapılan analizlerin sonucuna göre diri odunda teğet kesit etkili olurken, öz odunda radyal kesit etkili olmuştur.

Uygulama öncesi ağaç türlerinin pürüzlülük değerleri belirlenmiş, istatistiksel değerlendirmede $\mathrm{Rz}$ değerleri kullanılmıştır. Ladin odununda ağartma işlemlerinin 
\% pürüzlülük üzerine, öz ve diri odun, radyal ve teğet kesitte etkilerini incelemek için yapılan varyans analizi sonuçları ladin odununda ağartma işlemleri sonucunda $\%$ pürüzlülük değerlerinde, öz ve diri odunun etkisinin \%0.1 önem düzeyinde etkili olduğu, kesit türünde ise $\% 5$ yanılma olasılığı ile önemsiz olduğu, ağartma maddelerinin etkisi ise $\% 0.1$ yanılma olasılığı ile etkili bulunmuştur. Radyal ve teğet kesit \% pürüzlülük üzerine etkili olmamıștır. Ağartma maddelerinde ise oksalik asit ile ağartma $68.488 \mu \mathrm{m}$ değeri ile daha fazla bir pürüzlülük değișimi meydana getirmiştir. Ladin odununda ağartma işlemlerinin \% pürüzlülük üzerine radyal ve teğet kesitte etkilerini incelemek için yapılan analizlerin sonucuna göre diri odunda teğet kesit etkili olurken, öz odunda radyal kesit etkili olmuştur.

Sonuç olarak, ladin odunda renk değişimi üzerine öz ve diri odunun bir etkisi yoktur. Ladin odununda renk değişimi üzerine kesit türünün bir etkisi yoktur. Ladin odununda renk değişiminde perasetik asit ile ağartma işlemi iyi performans göstermiştir. Ladin odununda yüzey pürüzlülüğü üzerine öz ve diri odunun bir etkisi yoktur. Ladin odununda yüzey pürüzlülüğü üzerine kesit türünün bir etkisi yoktur. Ladin odununda yüzey pürüzlülüğünde en yüksek performans oksalik asit ile ağartma işleminde görülmüştür.

\section{KAYNAKLAR}

Allen, K.W. (1978). A review of contemporary views of theories of adhesion, J. Adhes., 21(3-4), 261-277.

Anonym, (1987). Furniture and Joinery for Devoloping Countries, UNIDO, Unido Publication No.: E. 88.III, Vienna.

Davis, E.M. (1962). Machining and related characteristics of United States Hardwoods. Technical Bulletin No: 1267, US Department of Agriculture-Forest Service, Washington, DC, 1962.
Jaic, M.; Zivanovic, R.; Stevanovic-Janeziz T;. Dekanski, A. (1996). Comparison of surface properties of beech and oakwood as determined by ESCA Method. Holz Roh-und Werkstoff, 54, 37-41.

Kollmann, F.F.P. \& Cote, W.A. (1984). Principles of wood science and technology. Vol. I, Springer, Berlin $162 \mathrm{pp}$

Meijer, M.DE. \& Militz, H. (2000). Wet adhesion of lowVOC coatings on wood a quantitative analysis, Prog. Org. Coat., 38, 223-240 (Elsevier Science).

Ozdemir, T. \& Mengeleoglu F. (2008). Some Properties of Composite Panels Made from Wood Flour and Recycled Polyethylene, International Journal of Molecular Sciences, 9(12), 2559-2569.

Pearce, E.M. (1987). Improving the performance of paint on timber. Wood and cellulosics: Industrial utilisation, Biotechnology,Structure and Properties, 5, 529-538.

Richter, K., Feist, W. \& Knaebe, M. (1995). The effect of surface roughness on the performance of finishes: 1 . Roughness characterization and stain performance. Forest Products Journal, 47 (7/8), 1-97.

Seman, M.S.A. (1995). Finishing properties of Acacia mangium, Paraserianthes falcataria and Gmelina arborea timbers: some Important parameters, $J$. Trop. For. Prod., 1(1), 83-89.

Suleman, Y. \& Rashid, S. (1999). Chemical treatment to improve wood finishing. Wood and Fiber Science, 31(3), 300-305.

\section{*Corresponding author's:}

Özlem BOZDOĞAN BALÇIK

Karadeniz Technical University, Faculty of Forestry, Department of Forest Industry Engineering, Trabzon, Turkey. \E-mail: ozlembozdogan25@gmail.com

ORCID: https://orcid.org/0000-0002-9898-8154 